Please send trade news information and illustrations to Arveen Bajaj at the $B D J$, Nature Publishing Group, The Macmillan Building, 4-6 Crinan Street, London N1 9XW.

Trade news is provided as a service to readers using text and images from the manufacturer, supplier or distributor and does not imply endorsement by the $B D J$. Normal and prudent research should be exercised before purchase or use of any product mentioned.

\section{Hygiene on the go}

New 'Brush-Aways' from Oral B are an instant teeth cleaning and breath freshening product that complements regular brushing and flossing.

The packets are small and compact; ideal for pockets and purses, and their minty taste can leave breath fresh and teeth and gums feeling clean. Designed to slip comfortably over any finger size, Brush Aways can be used 'on the go', to provide clean teeth and fresh breath anywhere.

Samples of Brush-Aways (supplied in a compact dispenser) will be available for practices to give away to their patients whilst stocks last. Please contact your local representative.

Reader response number 50

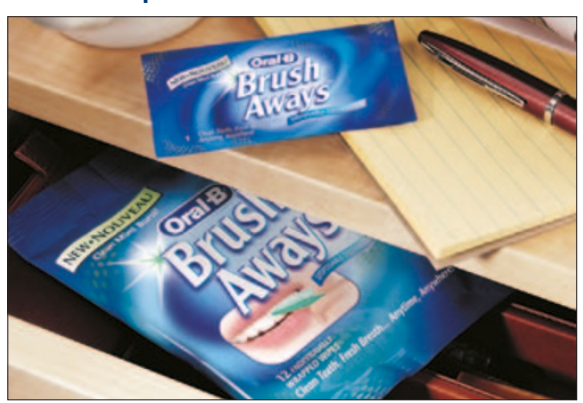

\section{Money saver}

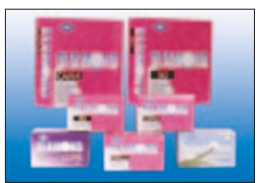

Kemdent are running a special offer on their Diamond restorative cements range. By buying Diamond Carve or 90 you can save money when you purchase Diamond Core on orders before 31st March. Diamond adheres to dentine and enamel, is fluoridereleasing and radiopaque. Diamond Carve has a slightly longer working time which enables you to carve and shape the restoration if necessary while Diamond 90 offers a fast 90 second set. Diamond Core is specially designed for core build-up, comes in a distinctive light blue shade with a fast working time of only 125 seconds from the start of the mix.

Reader response number 52

\section{TRADE NEWS}

WHAT'S NEW

\section{Easy Endo}

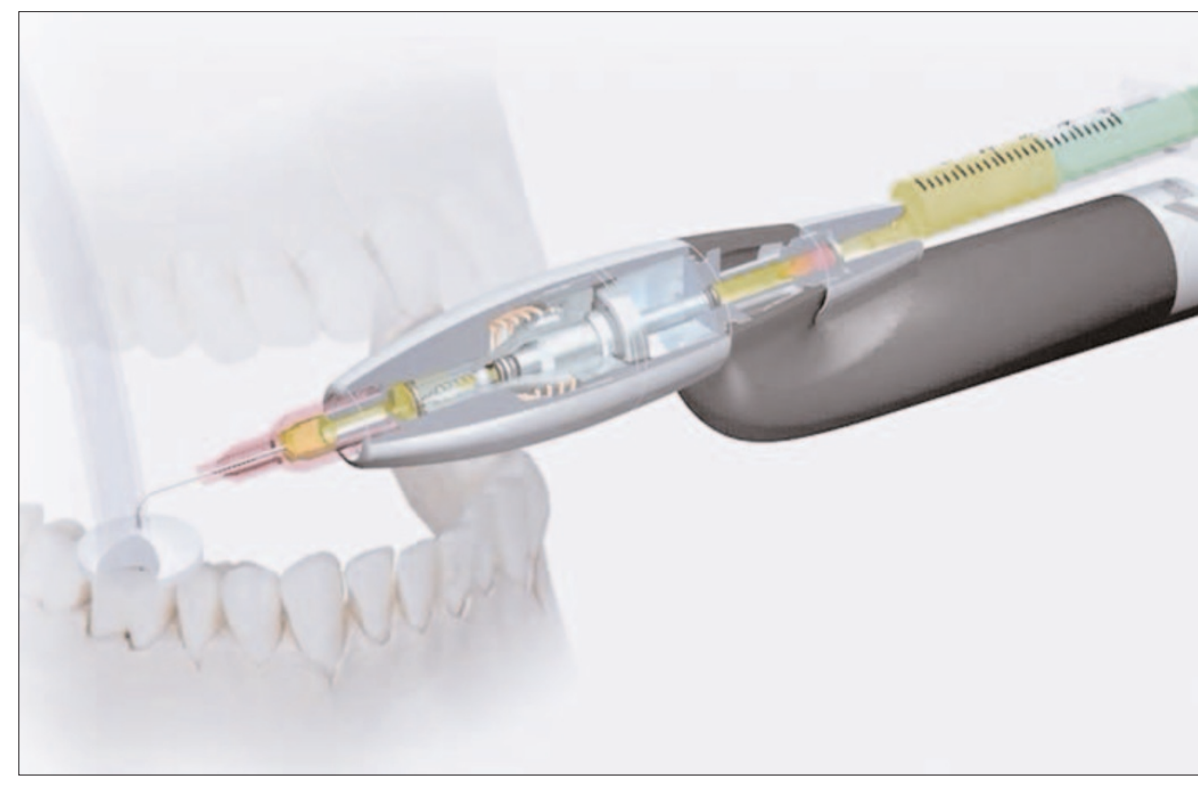

New RinsEndo from Dürr Dental can overcome the inaccessibility and lack of sight problems during endodontic treatment. Chemical root canal treatment can be achieved effortlessly since RinsEndo can be attached to a range of different manufacturers' turbines to effectively cleanse root canals.

It is designed for use in conjunction with all known rinsing solutions and requires no other equipment. RinsEndo allows the user to penetrate deep into the root canal right down to the apex and roots are irrigated and cleansed with minimal spray.

Reader response number 51

\section{Enhanced website}

The BDTA has recently launched its re-designed website. The enhanced editorial and picture content will make the website more informative and the re-organisation of the content will make the site more user friendly to both the trade and the profession.

Information about the BDTA has been separately targeted towards the trade and the profession to highlight the BDTA's services of relevance to each group. For the dental profession, the BDTA is using the website to promote the importance of buying from and dealing with BDTA members, who abide by a code of conduct.

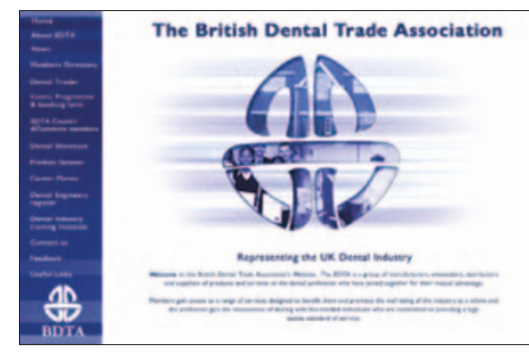

The news page will be updated regularly with information about the latest activities and achievements of the BDTA and member companies while member information has been tabulated to make it easier to locate specific details about BDTA member companies.

It also features links to almost 100 useful dental related websites for organisations based in both the UK and abroad.

Reader response number 53 


\section{Cleaning attachment}

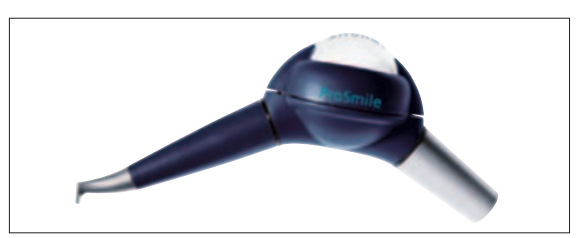

The ProSmile Handy tool from Sirona provides an effective method of prophylactic air abrasive polishing for removal of plaque from all tooth surfaces.

The product is completely adjustable and can be used with an interchangeable $90^{\circ}$ or $120^{\circ}$ angle spray tip for optimum access, and there is a large capacity chamber to provide adequate powder supply for more than one patient. The design of the ProSmile Handy ensures a balanced and relaxed operation by the user and can be used for the effective and minimally invasive removal of plaque to the patient. It comes with the Sirona Click \& Go interface allowing the unit to be attached to most popular brands of handpiece couplings and the design ensures a balanced feel for fatigue-free operation.

Reader response number 54

\section{Infection protection}

Septodont's Quitanet S.A. is a non-toxic, non-irritant blend of non-ionic quaternary compounds, which act together with a condensated detergent. The aldehyde-free preparation effectively disinfects and cleans stainless steel, aluminium, glass, rubber and plastics. When diluted, the solution has a close-to-neutral $\mathrm{pH}$ and exhibits a low-to-zero hazard potential whether on ingestion, eye contact, or inhalation.

As with all of Septodont's products, Quitanet S.A. is formulated specifically for use in dentistry.

Reader response number 56

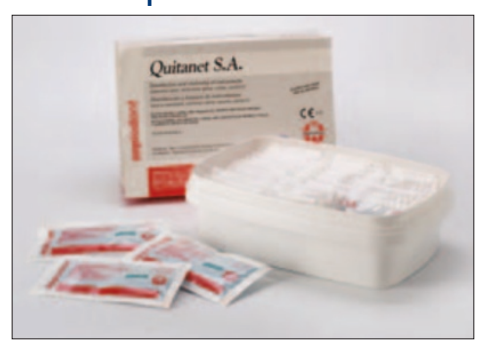

\section{Protecting instruments}

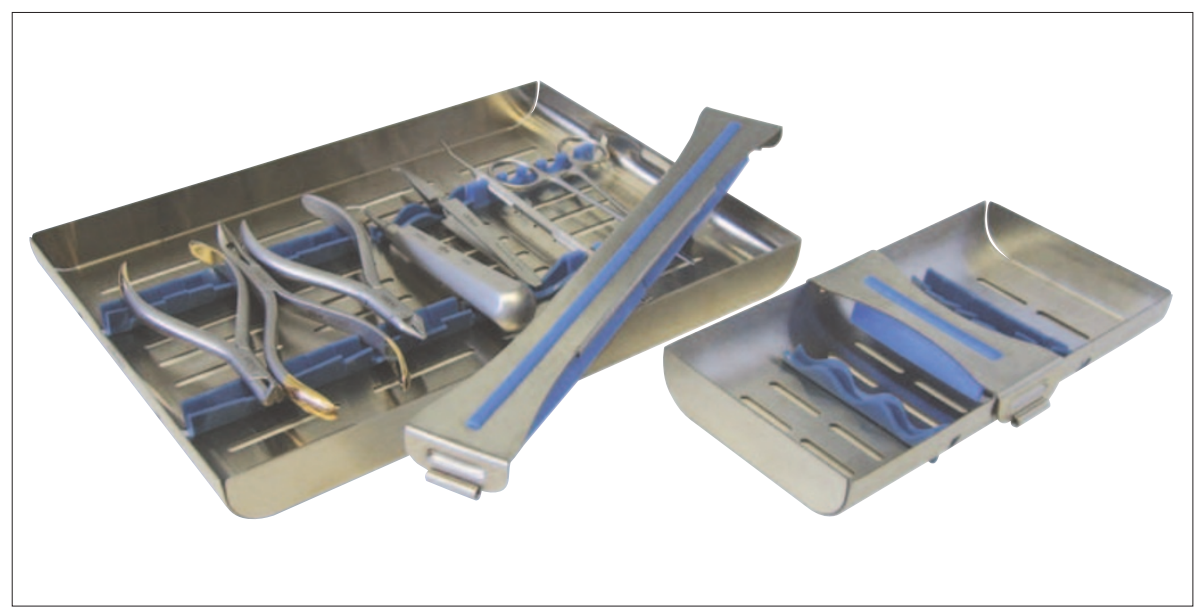

DB Orthodontics Limited are pleased to announce the availability of their new DBO sterilisation cassette range which is designed to secure and protect surgery instruments during the sterilisation procedure.

DBO sterilisation cassettes are manufactured from stainless steel with a deep draft to safely enclose all instruments used within an orthodontic or general practice. They also feature a choice of autoclavable

\section{Healthy hands}

Septodont's Quitanet S.A. is a non-toxic, non-irritant blend of non-ionic quaternary compounds, which act together with a condensated detergent. The aldehyde-free preparation effectively disinfects and cleans stainless steel, aluminium, glass, rubber and plastics. When diluted, the Gojo skin care regimen, from Trycare helps maintaining clean, healthy hands. It consists of Gojo Antibacterial Lotion Soap, Gojo Anitbac Lotion Soap and Purell Instant Hand Sanitizer.

Gojo Antibacterial Lotion Soap kills microorganisms, but is gentle on hands even after repeated daily washing. It contains chloroxylenol quick-acting antimicrobial agent, is fragrance free and has a non-drying formula containing moisturisers to facilitate frequent use.

Gojo Anitbac Lotion Soap has the same basic features and benefits, plus an effective degreasing agent while Purell Instant Hand Sanitizer can kill common microorganisms in as little as 15 seconds and is the most convenient way to help reduce cross infection via the hands. The products are convenient to use as no water or towels are required and evaporate quickly to leave hands feeling soft and refreshed. The solution has a close-to-neutral $\mathrm{pH}$ and exhibits a low-to-zero hazard potential whether on ingestion, eye contact, or inhalation.

As with all of Septodont's products, Quitanet S.A. is formulated specifically for use in dentistry. Reader response number 57

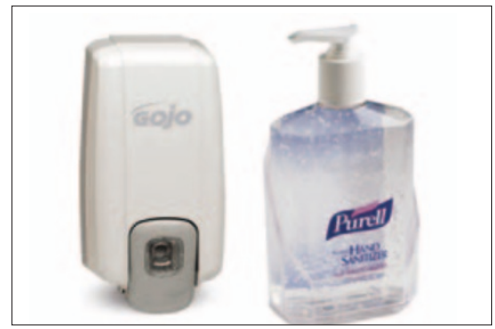




\section{Fighting super bugs}

Sterinis is a new, high-tech device that destroys infectious agents by attacking them with tiny particles of disinfectant in a dry mist. Originally developed in Toulouse, France to prevent the spread of 'super bugs' in hospitals, this programmable device is able to disinfect any surface and neutralise infection black spots, even those that are impossible to reach by hand.

The transportable nature of Sterinis means that it can be deployed easily to provide continuous protection against cross infection in a wide variety of medical, paramedical, and other environments. It costs $£ 4,999$ excluding VAT and is available from BES Decon, a division of BES Rehab Ltd. Reader response number 58

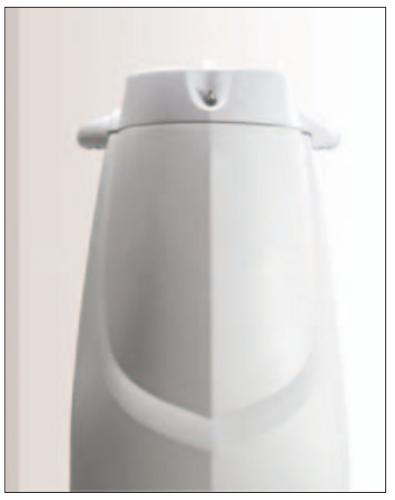

\section{Disinfection for impression materials}

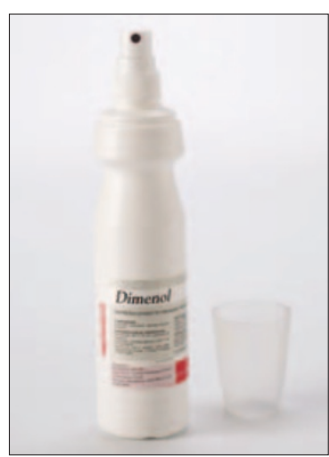

Formulated with isopropyl alcohol, Septodont's Dimenol is designed specifically to disinfect impression materials - alginates and silicones - to protect patients, practice professionals, laboratory professionals and the prosthesis itself.

Spray sufficient bactericidal, fungicidal and virucidal Dimenol evenly onto the impression materials to moisten, leave for 15 minutes and rinse carefully to effectively decontaminate the blood, saliva and proteins that can harbour pathogens.

Supplied in 200ml spray bottles, Dimenol disinfects without altering the surface accuracy and without producing any dimensional variation.

Reader response number 59

\section{Washer decontaminator}

Hydrojet from Professional Dental Supplies, is the first washer decontaminator which incorporates 'Forced Wave Technology'. When used with the micro-biocidal cleaning agent Hydrosol Liquid, it can reduce the microbial count to zero after a full cycle, and raises water temperatures to over 60 degrees.

The stylish and compact design takes up minimal space, yet still accommodates five shelves in the main tank for processing instruments and dental apparatus.

The Hydrojet offers a choice of two thorough wash cycles, the full standard cycle of 25 minutes or a 15 minute economy cycle when instruments are needed quickly.

Reader response number 60

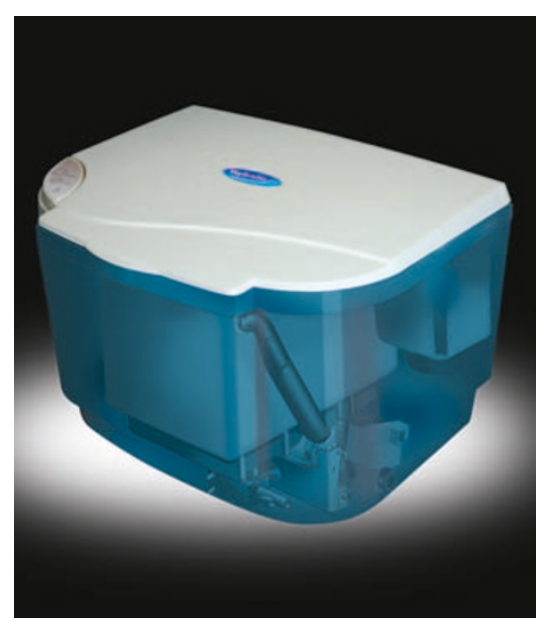

\section{Disposable system}

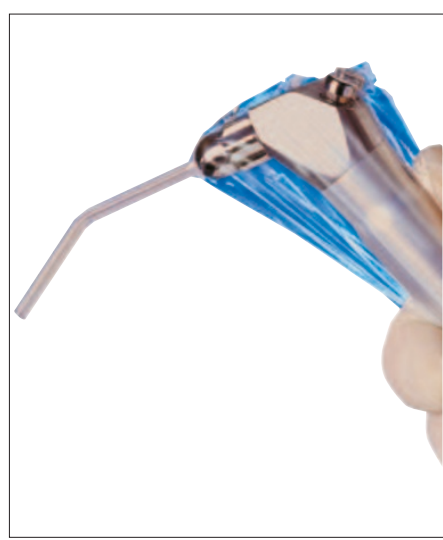

SaniTip disposable air and water (3-in-1) syringe system from Dentsply can address problems of water droplets in dry air reducing the strength of bonds. It replaces an autoclaved metal tip with a single-use, clear plastic tip, attached to a syringe with an adapter (provided free of charge to all new users).

When a SaniTip is fully seated in the adapter, a selfsealing water channel is created guaranteeing dry air with optimal pressure. Even the repeated insertion and removal of the original metal tip can destroy the o-ring inside the syringe which separates the air and water. And because it's disposable there are no cross-infection control worries.

Reader response number 61 